\title{
Evolution of the electrical contact of dynamic pantograph-catenary system
}

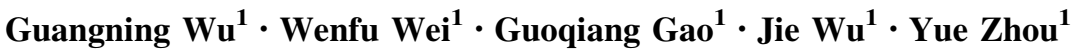

Received: 29 October 2015/Revised: 18 March 2016/Accepted: 19 March 2016/Published online: 9 April 2016

(C) The Author(s) 2016. This article is published with open access at Springerlink.com

\begin{abstract}
A good contact between the pantograph and catenary is critically important for the working reliability of electric trains, while the basic understanding on the electrical contact evolution during the pantograph-catenary system working is still ambiguous so far. In this paper, the evolution of electric contact was studied in respects of the contact resistance, temperature rise, and microstructure variation, based on a home-made pantograph-catenary simulation system. Pure carbon strips and copper alloy contact wires were used, and the experimental electrical current, sliding speed, and normal force were set as $80 \mathrm{~A}, 30 \mathrm{~km} / \mathrm{h}$, and $80 \mathrm{~N}$, respectively. The contact resistance presented a fluctuation without obvious regularity, concentrating in the region of 25 and $50 \mathrm{~m} \Omega$. Temperature rise of the contact point experienced a fast increase at the first several minutes and finally reached a steady state. The surface damage of carbon trips in microstructure analysis revealed a complicated interaction of the sliding friction, joule heating, and arc erosion.
\end{abstract}

Keywords Pantograph-catenary system - Electrical contact - Electric trains - Contact resistance . Temperature rise $\cdot$ Microstructure

\section{Introduction}

Pantograph-catenary system bears the task of energy transfer from the electrical power grid to electric trains; therefore, the electrical contact between the pantograph

Wenfu Wei

wfwei@home.swjtu.edu.cn

1 School of Electrical Engineering, Southwest Jiaotong University, Chengdu 610031, China and catenary is directly related with the working reliability and safety of the trains. In the working situation, the overhead contact wire and sliding strip suffer from the multiple impacts of zigzag sliding friction, joule heating, and offline arcing erosion, which make the evolution of electrical contact rather complex. Especially the random arcing become more predominant at higher speed, heavier load, and cold weather conditions, which has already turned into a great obstacle for the stable current collection [1].

Among the great amounts of researches related with the pantograph-catenary system, large efforts were made on the mechanical vibration coupling analysis, aerodynamic force calculation, and active control design [2-5]. Relatively, researches on the electrical contact itself were paid less attention to. Besides the comparison of friction wear properties under different current and speed conditions [6, 7], there were also constant interests in the electrical temperature characteristics [8], conducted and radiated electromagnetic emission, etc. [9, 10]. All the above studies were closely related to the electrical contact of the pantograph-catenary system and therefore, possess significant importance to prompt the development of high-speed railway technology.

However, most previous researches were focused on only one or two aspects of the electrical contact and could reveal limited information on the dynamic evolution process. Simultaneous investigations into the different aspects of the electrical contact, such as the conductivity variation, temperature rise, as well as the microstructure characteristics, would be absolutely helpful for a better understanding of the pantograph-catenary system.

In this work, a comprehensive study on the sliding electrical contact of a pantograph-catenary system was carried out. Simultaneous voltage and current were 
recorded to obtain the conductivity property, while infrared thermometry was utilized to get the temperature rise. In the end, the surface damages and material transfer were studied through microstructure analysis. Experimental results of this paper may help reveal the physical mechanisms for the sliding electrical contact of pantograph-catenary system and also provide a benchmark for the modeling of pantograph-catenary system.

\section{Experimental setup}

\subsection{The pantograph-catenary simulation test system}

Considering the real working conditions of a pantographcatenary system, a set of pantograph-catenary contact test apparatus was set up. As shown in Fig. 1, this experimental system consisted of an AC power source, adjustable resistance, inductance loads, a rotating wheel, and a carbon strip; a partial photo of the experimental apparatus is given in Fig. 2. The AC power source adopted the electricalelectronic technology and effectively realized a stable output current from 0 to $200 \mathrm{~A}$ in a compact structure. The adjustable resistance and inductance were used to simulate the different train loads. The copper alloy wire with a realistic geometry was fixed in the groove around the outer edge of the rotating wheel. The pantograph strip, made of carbon materials, was housed on a carriage driven by two different motors. The rotating movement of contact wire and the horizontal translation of pantograph strip successfully realized the zigzag motion in the real working condition. Furthermore, the pantograph strip could move in the vertical direction to simulate the switch status. During the experiments, the electrical current came from the constant current power source, passing through the contact wire, the pantograph strip, and the adjustable resistive-inductance load, and eventually went back to the power source. The

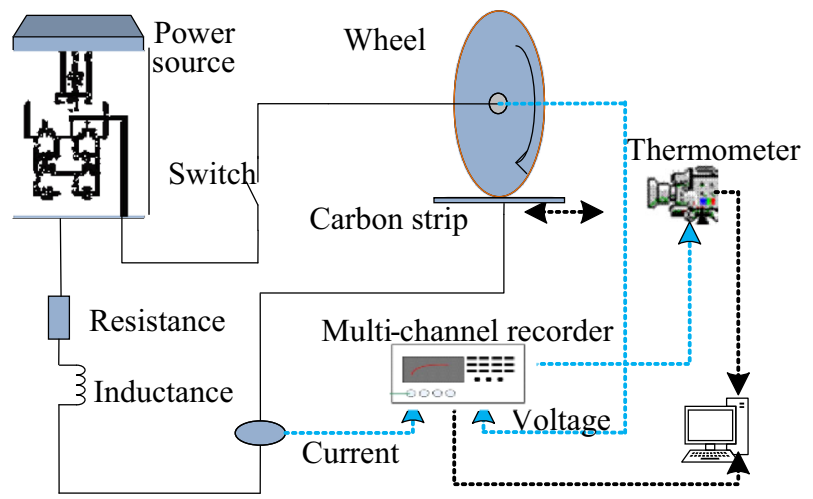

Fig. 1 Layout of the experimental setup

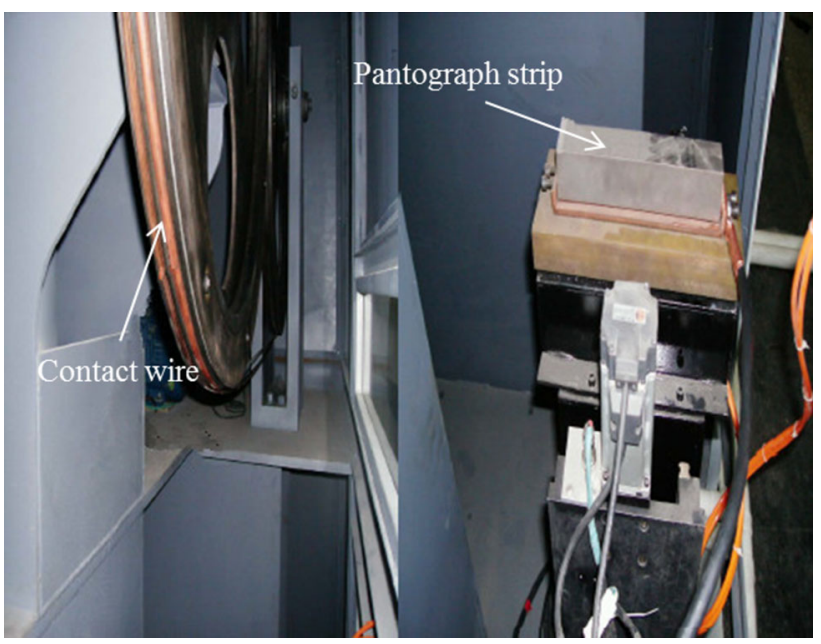

Fig. 2 Partial physical photo of the experimental apparatus

above electrical layout was similar to that of a real working pantograph-catenary system.

In this work, experimental parameters of the electrical current, sliding speed, and normal force was fixed as $80 \mathrm{~A}$, $30 \mathrm{~km} / \mathrm{h}$, and $80 \mathrm{~N}$, respectively. The running time of each experiment was lasted for $10 \mathrm{~min}$.

\subsection{Measurement methods}

The contact voltage across the wheel and strip was measured by a 1,000:1 high voltage probe (TPP0250, Tektronix), while the current was measured by a Rogowski coil (i400s, Fluke). The two-dimensional infrared images containing temperature information were recorded by an infrared thermometer (NS9500, NEC InfraRed Camera) with a record speed of five frames per second. It is worth noting that since the most previous study on the temperature characteristics utilized a thermocouple probe buried in the strip, our infrared measurement provided a non-intrusive as well as spatial-resolution detection.

The electrical signals were both stored into a multichannel recorder, with a constant sampling frequency of $1 \mathrm{kHz}$. Thermometer could be triggered either manually or automatically. After the experiments, the carbon strip was disassembled for microstructure examination by a scanning electron microscope.

\section{Results and discussions}

\subsection{Characteristics of electrical parameters}

Parts of the contact voltage and current waveforms are shown in Fig. 3. Both of the waveforms hold a sinusoidal shape on the whole, except for the several voltage 


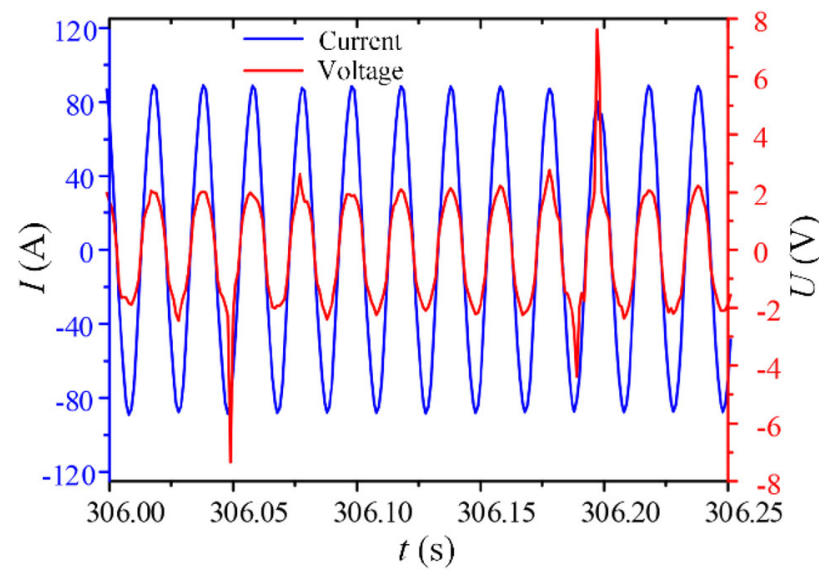

Fig. 3 Contact voltage and electrical current with time

distortion regions which were probably accompanied by pantograph arcing or sparking. The phase of voltage waveform stays the same as that of current waveform, due to the resistive properties of the contact area. Amplitude of the contact voltage reaches around $2 \mathrm{~V}$. The sharp changes of contact voltage, for example at 306.05 and 306.19 s, were directly resulted from the steep drop of contact force, which was expected to induce the occurrence of pantograph arcing. According to our previous study on the pantograph arcing, the resistance of arc plasma was generally one order of magnitude higher than the normal contact resistance.

The occurrence of pantograph arcing not only distorted the electrical power quality, but also resulted in the severe temperature rise on the electrodes surfaces, ablated material, and worsen the current collection system damages. The primary cause for the pantograph arcing should be attributed to the unexpected vibration between contact wire and strip due to the geometry singularity. Therefore, the occurrence of pantograph arcing was quite random, which

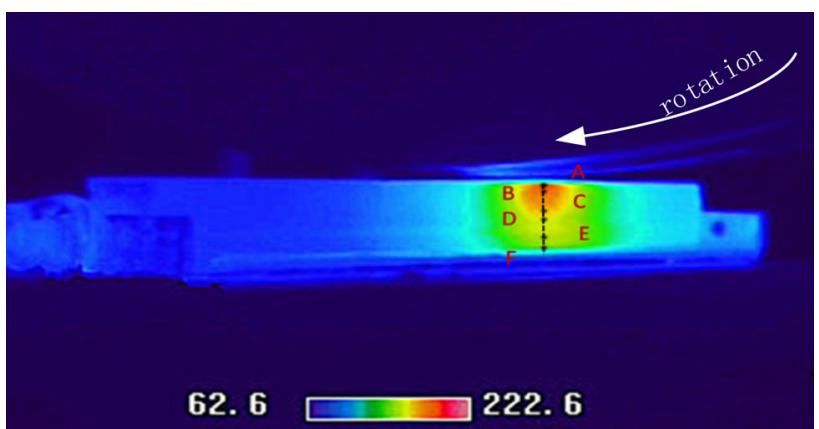

Fig. 5 Typical infrared image of the pantograph strip

brought in great difficulties in the study of electrical contact properties. Previous researches have shown that the occurrence probability increased as the running speed got higher, while the arc erosion became much more serious [11]. Although the comprehensive impacts of arcing on the surface damages were still not clarified well, the electrical parameter characteristics had been well analyzed based on the classic Cassie-mayr's equation [12, 13], while the evolution of spatial temperature distribution could be further surveyed by the magnetic-hydrodynamic theory.

\subsection{Contact resistance with time}

From the above discussion, the electrical contact exhibited an ideal resistive property. Therefore, the contact resistance $R$ could be directly obtained using the Ohm's law, $R=$ $U / I$, where $U$ and $I$ were the experimentally recorded contact voltage and current, respectively.

The deduced contact resistance with time is shown in Fig. 4, with an inset for the variation of the contact resistance in a shorter time. Results indicate that the contact resistance was concentrated in the region of 25 and $50 \mathrm{~m} \Omega$

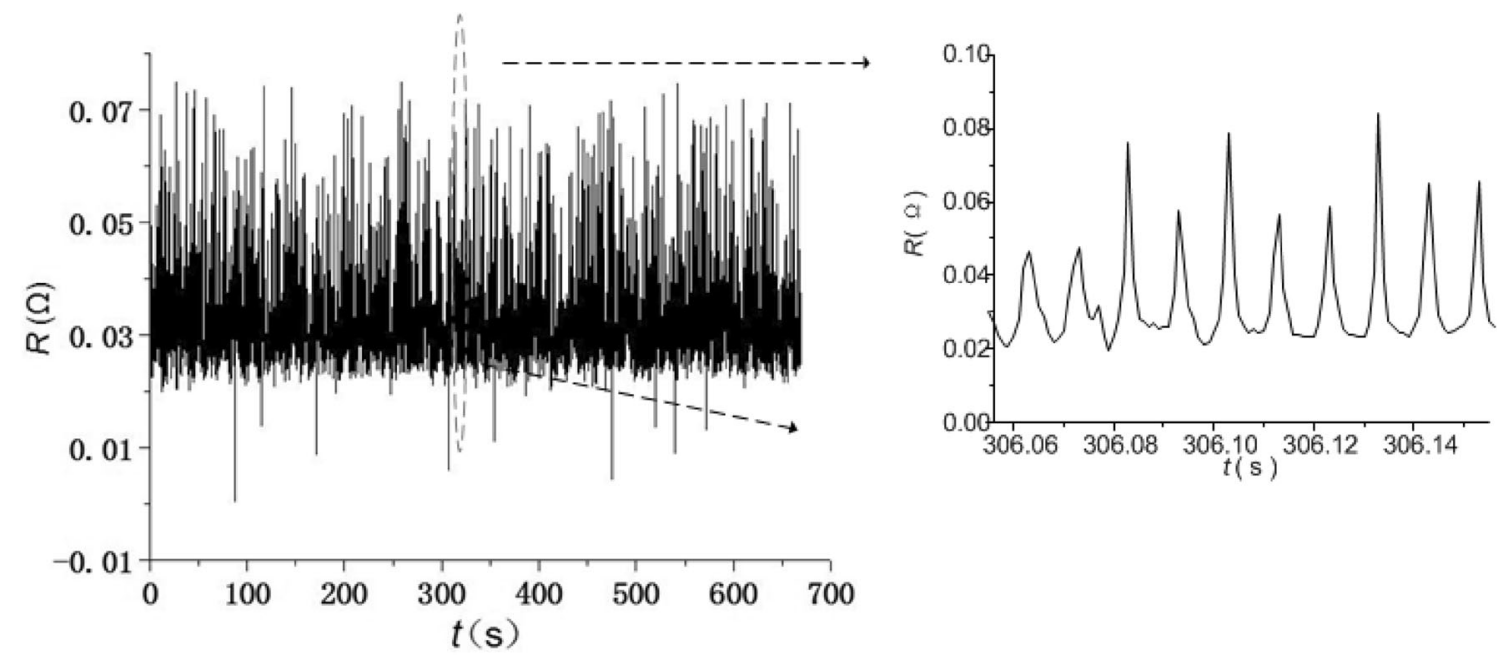

Fig. 4 Variation of the contact resistance with time 
during the entire period and experienced a relatively small fluctuation. The fluctuation period was $10 \mathrm{~ms}$, just a half cycle of the AC power frequency. We regarded that the regular crossing zero of AC current contributed to the regular rise of contact resistance. The fluctuation irregularity in resistance values could be explained from the variation of effective contact area. The effective contact area was the actual contact parts from the microscopic aspect, which suffered from the friction work, joule heat, and/or arcing erosion. During the constant sliding process with current, the effective contact area was always going through a dynamic variation of being destroyed and reformation from one place to another. Therefore, the contact resistance depended on the effective contact area and experienced an obvious fluctuation. On the other hand, the average contact resistance was highly depended on the contact force, material resistivity, running speed, and current. The former two parameters determined primarily the static contact resistance, while the latter two parameters influenced the dynamic variation process significantly.

\subsection{Temperature distribution of pure carbon strip}

Material properties, such as resistivity, hardness, and friction coefficient, are temperature dependent, and will influence the final wear loss level of the material. Hence an investigation on temperature characteristic during the pantograph-catenary working is quite necessary. Typical infrared image of the pantograph strip is shown in Fig. 5. It can be seen that the highest temperature was just located at the contact point of the pantograph strip and contact wire. With the distance away from the contact point increasing, the temperature decreased gradually. On the whole, a Gaussian-like temperature distribution in the pantograph strip could be found. The temperature of the contact wire remained at quite low level due to the constant rotation.

The temperature variation of the pantograph strip with time is shown in Fig. 6, where typical infrared images at

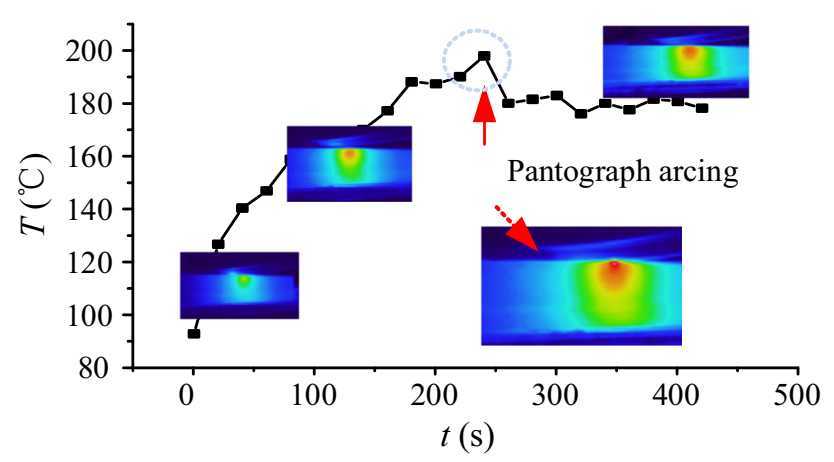

Fig. 6 Maximum temperature of pantograph strip, with typical infrared images inset
Table 1 Temperature distribution of pure carbon strip

\begin{tabular}{lllllll}
\hline & A & B & C & D & E & F \\
\hline$T\left({ }^{\circ} \mathrm{C}\right)$ & 157.5 & 178.2 & 147.9 & 138.5 & 129.4 & 91.7 \\
\hline
\end{tabular}

different stages are also given. It should be noticed that the time at zero was shortly after the previous experiment, and local regions of the pantograph strip were still in warm state. Nevertheless, the overall variation in Fig. 6 still properly represents the temperature rise process. It can be found that after a fast temperature rise stage during the first several minutes, the pantograph strip came to a relative steady state of around $175^{\circ} \mathrm{C}$ finally. During this process, pantograph arcing could take place, resulting in the surface temperature to reach $200{ }^{\circ} \mathrm{C}$ for a short period. For the final steady state, spatial temperatures at six typical locations as shown in Fig. 5 are given in Table 1.

It is worth mentioning that the contact resistance was significantly influenced by both the material resistivity and the condition of contact spots according to the classical electrical contact theory. On the one hand, the resistivity of copper changed little with the temperature rising from 100 to $200{ }^{\circ} \mathrm{C}$, considering that the temperature coefficient of copper resistance was only $0.00393 /{ }^{\circ} \mathrm{C}$. On the other hand, the number and radius of contact spots could change obviously due to the high temperature at the contact area, accompanied with material softening. To make clear the accurate effects of temperature on the whole contact resistance, it is necessary to conduct experiments at constant temperatures of different levels in the future work.

\subsection{SEM observation of the worn surfaces of pure carbon strips}

Surface conditions of the carbon strip before and after the experiments are given in Fig. 7. As shown in Fig. 7a, the surface of the original pure carbon strip is very smooth without wear scar. After several minutes of sliding between

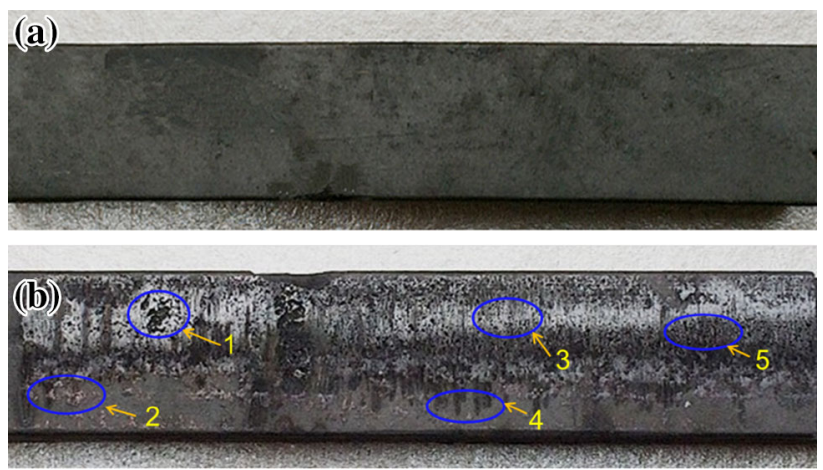

Fig. 7 Surface morphologies of pure carbon strips before (a) and after (b) test 
pantograph strip and catenary wire, a new surface morphology with pits and craters appeared, as shown in Fig. 7b. The new morphologies were generally classified as the following five types (corresponding to regions $1-5$ in Fig. 7, respectively):

- Craters Diameters of typical craters could reach as high as several millimeters. Serious arc discharge accompanying the high-speed friction would be major contributions to the formation of craters.

- Dull-red area There were irregular dull-red areas distributed on the strip surface, indicating that the material of copper alloy wire was gradually transferred to the strip. This area would be referenced as material transfer area hereinafter.

- Bright area White bright area was much brighter than the basic carbon materials, which could possibly result from the deposition of oxidative materials.

- Dark stream line Dark stream line was in the same direction of the contact wire rotation.

- Pits There were great amounts of pits, with much smaller diameter than the crater, widely distributed on the strip surface.
Both the dark stream line and the pits could be the direct evidence of arc discharge occurrence.

The typical microstructures in different areas of the pantograph strip are shown in Fig. 8. Figure 8a presents the original strip surface used for comparison, and Fig. $8 \mathrm{~b}-\mathrm{d}$ is the enlarged pictures of material transfer area, bright area, and arc ablation area, respectively. By comparing the surface pictures before and after test, we can find that the surface of strip became bumpy, and a large number of wear debris, arc ablation craters, and spalling blocks appeared. Meanwhile, some flake-like fragments can also be found from the worn surface.

When the pantograph strip rubbed against the catenary wire with the current, arc discharges occurred frequently because of the air gap of pantograph-catenary system breakdown. A lot of heat was generated on the contact surface, which included arc heat, Joule heat, and friction heat, resulting in the plastic deformation of material. The high temperature generated by the pantograph-catenary arc would ablate pantograph strip and catenary wire, simultaneously melting metal material and gasifying carbon
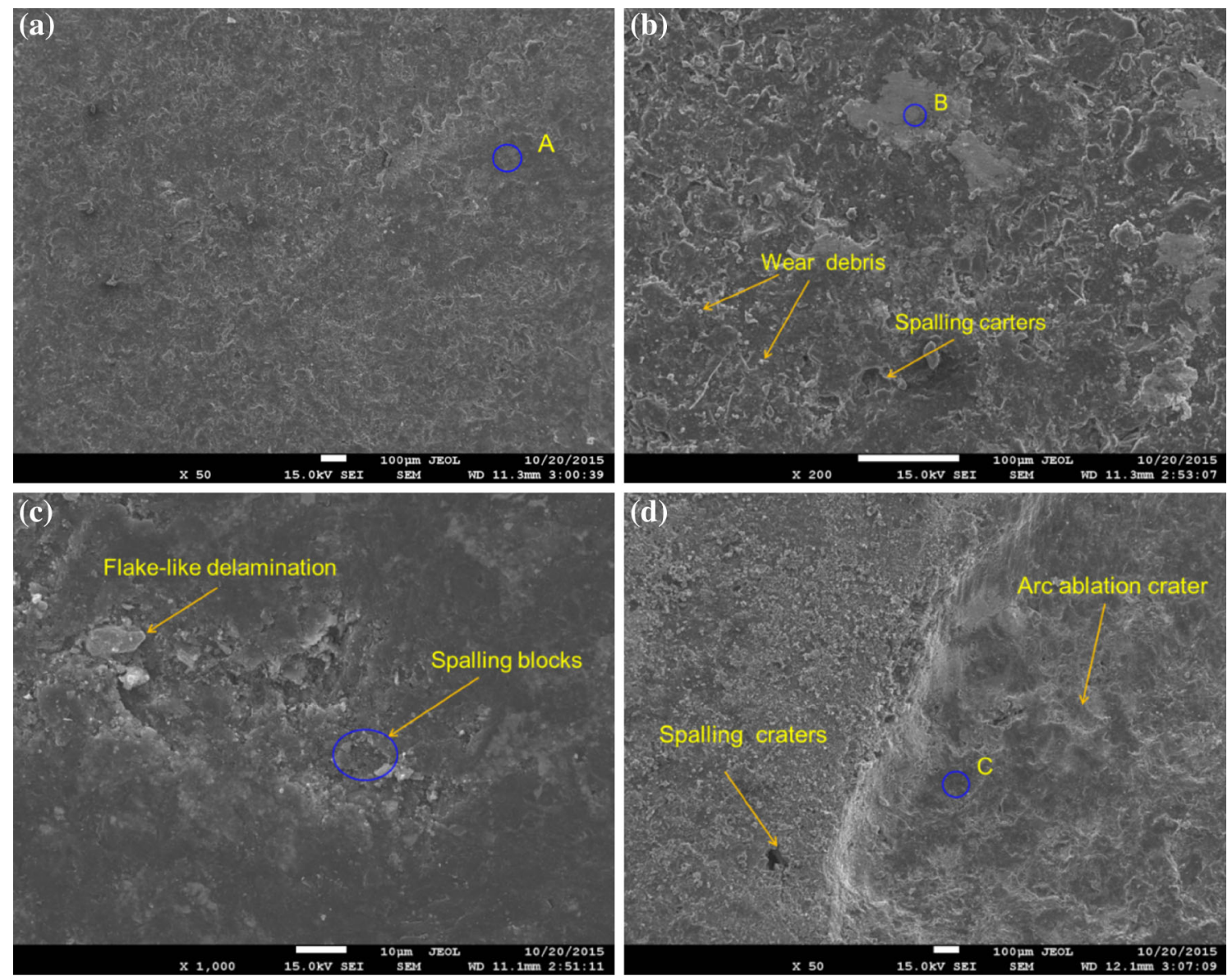

Fig. 8 SEM images of pure carbon strips in four different cases. a Original surface before test. b Material transfer area. c Bright area. d Arc ablation area 

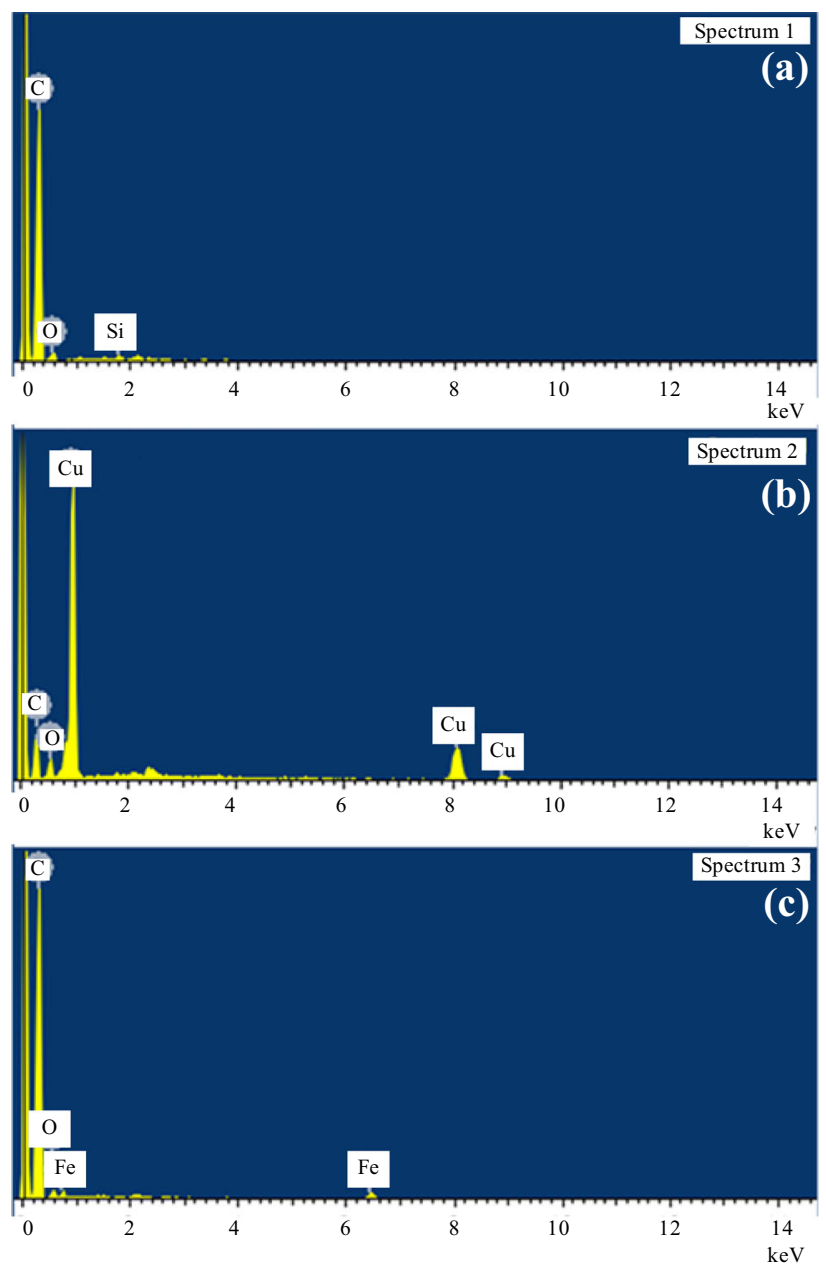

Fig. 9 EDX spectrums of pure carbon strips in three regions. a Original area. b Material transfer area. c Arc ablation area

Table 2 Elementary composition of the original area

\begin{tabular}{lll}
\hline Element & Mass percentage $(\%)$ & Atomic percentage $(\%)$ \\
\hline $\mathrm{C}$ & 39.69 & 48.24 \\
$\mathrm{O}$ & 52.00 & 47.44 \\
$\mathrm{Si}$ & 8.31 & 4.32 \\
\hline
\end{tabular}

material from the pantograph strip and contact wire [14]. As a result, the number of real contact points on the contact surface decreased, and the electrical contact condition of the pantograph-catenary system tended to deteriorate. The friction force, friction heat, and shear force all increased, producing a few of wear cracks. With the sliding continually going on, flake-like delaminations (Fig. 8c) were formed on the contact surface. That was attributed to the serious material adhesion caused by high temperature, and the fracturing delamination caused by shearing force and normal stress. The flake-like delaminations would further evolve into spalling blocks by shearing force, as shown in
Table 3 Elementary composition of the material transfer area

\begin{tabular}{lcc}
\hline Element & Mass percentage $(\%)$ & Atomic percentage $(\%)$ \\
\hline $\mathrm{C}$ & 1.33 & 5.56 \\
$\mathrm{O}$ & 7.15 & 22.37 \\
$\mathrm{Cu}$ & 91.51 & 72.07 \\
\hline
\end{tabular}

Table 4 Elementary composition of the arc ablation area

\begin{tabular}{lll}
\hline Element & Mass percentage (\%) & Atomic percentage (\%) \\
\hline $\mathrm{C}$ & 22.81 & 44.55 \\
$\mathrm{O}$ & 23.04 & 33.79 \\
$\mathrm{Fe}$ & 32.79 & 13.77 \\
$\mathrm{Cu}$ & 21.36 & 7.89 \\
\hline
\end{tabular}

Fig. $8 \mathrm{~b}$ and c. In addition, we can find a large number of debris on the surface of the strip in Fig. 8b. It could be concluded that abrasive wear had played an important part in material transfer process. There are several craters distributed on the strip in Fig. 8d, which could be the evidence of intense arc discharges. In summary, in the whole process of rubbing, the temperature rise of the contact couple was an important factor which had a significant influence on the wear rate of the pantograph-catenary system.

Furthermore, the original area, arc ablation area, and material transfer area were measured by energy dispersive $\mathrm{X}$-ray spectroscopy (EDX), and the results are shown in Fig. 9. The analyzed point in Fig. 9a corresponsds to the point A in Fig. 8a, where dominant carbon elements and slight oxygen and silicon elements could be seen. Specific element mass percentages are given in Table 2. As for the material transfer area corresponding to the point $\mathrm{B}$ in Fig. 8b, the EDX result revealed abundant copper material. The material transfer could be a result of a series of processes. During the process of rubbing, the hardness of materials could be effectively decreased by the temperature rise from several heat sources, and the interface between strip and wire would become more adhesive. The adhesive interface combined with frictional force could result in the material transformation from catenary wire to pantograph strip. The element percentage of material transfer area is shown in Table 3. In the arc ablation area, the spalling crater could be found on the surface of strip obviously. At the same time, the arc ablation pits and dark stream-lines were also the products of arc discharge. From the EDX measurement for point $\mathrm{C}$ in Fig. 8d, abundant carbon elements as well copper and iron elements could be discovered at the crater bottom area (Fig. 9c). Specific element mass percentages are given in Table 4. It suggests that material transfer also occurred from the copper contact wire to the strip during the crater formation, besides the 
previously described material transfer area. Therefore, the arc discharge could be expected as a significant factor resulting in the material transfer of pantograph-catenary system. However, the damage mechanism of the pantograph-catenary system included both mechanical and electrical wear. The accurate wear process would possibly be well understood by a multiple physics coupling simulation in the future work.

\section{Conclusion}

In this paper, the evolution of the electrical contact between pantograph and catenary was studied in respects of the electrical conductivity, temperature rise, as well as the microstructure variation. The following conclusions can be drawn.

- The contact resistance was majorly concentrated in the region of 25 and $50 \mathrm{~m} \Omega$, and a relative fluctuation without obvious regularity could be found.

- The temperature of the contact point experienced a fast rise int the first several minutes but finally reached a steady state of $175^{\circ} \mathrm{C}$. Spatial temperature exhibited a Gaussian-like distribution, and the random arc discharge could induce a sharp increase of local temperature.

- The evolution mechanisms were discussed from the microstructure analysis of five typical morphologies, and arc discharges was expected to be responsible for the formations of dark stream line, pits, and craters, while the material transfer process was dependent on adhesion wear and arc discharge.

Acknowledgments This work was supported by the National Natural Science Foundation of China (Nos. U1234202 and 51577158), the National Science Foundation for Distinguished Young Scholars of China (No. 51325704), and the Fundamental Research Funds for the Central Universities (No. A0920502051505-19).

Open Access This article is distributed under the terms of the Creative Commons Attribution 4.0 International License (http:// creativecommons.org/licenses/by/4.0/), which permits unrestricted use, distribution, and reproduction in any medium, provided you give appropriate credit to the original author(s) and the source, provide a link to the Creative Commons license, and indicate if changes were made.

\section{References}

1. Midya S, Bormann D, Larsson A, Schutte T, Thottappillil R (2008) Understanding pantograph arcing in electrified railwaysinfluence of various parameters. In: 2008 IEEE international symposium on electromagnetic compatibility, vols 1-3, pp 592-597

2. Zhang W, Zhou N, Li R, Mei G, Song D (2011) Pantograph and catenary system with double pantographs for high-speed trains at $350 \mathrm{~km} / \mathrm{h}$ or higher. J Mod Transp 19(1):7-11

3. Collina A, Bruni S (2002) Numerical simulation of pantographoverhead equipment interaction. Veh Syst Dyn 38(4):261-291

4. Chater E, Ghani D, Giri F, Haloua M (2015) Output feedback control of pantograph-catenary system with adaptive estimation of catenary parameters. J Mod Transp 160(4):257-266

5. Zhai WM, Cai CB (1998) Effect of locomotive vibrations on pantograph-catenary system dynamics. Veh Syst Dyn 29:47-58

6. Yang HJ, Chen GX, Gao GQ, Wu GN, Zhang WH (2015) Experimental research on the friction and wear properties of a contact strip of a pantograph-catenary system at the sliding speed of $350 \mathrm{~km} / \mathrm{h}$ with electric current. Wear 332:949-955

7. Yang HJ, Hu Y, Chen GX, Zhang WH, Wu GN (2014) Correlation between the wear and vibration of the contact strip in a contact wire rubbing against a contact strip with electrical current. Tribol Trans 57(1):86-93

8. Ge X, Liu WZ, Yang ZP, Wang YF (2014) The study on electrical temperature characteristics of high speed pantograph. In: 2014 IEEE transportation electrification conference and Expo (Itec) Asia-Pacific 2014

9. Tellini B, Macucci M, Giannetti R, Antonacci GA (2001) Conducted and radiated interference measurements in the line-pantograph system. IEEE Trans Instrum Meas 50(6):1661-1664

10. Midya S, Thottappillil R (2008) An overview of electromagnetic compatibility challenges in European rail traffic management system. Transp Res Part C Emerg Technol 16(5):515-534

11. Hu Y, Chen GX, Gao GQ, Wu GN, Zhang WH, Zhou ZR (2015) Study on material transfer in the process of contact strips rubbing against a contact wire with electric current. Proc Inst Mech Eng Part J J Eng Tribol 230:202-211

12. Liu YJ, Chang GW, Huang HM (2010) Mayr's equation-based model for pantograph arc of high-speed railway traction system. IEEE Trans Power Deliv 25(3):2025-2027

13. Li TZ, Wu GN, Zhou LJ, Gao GQ, Wang WG, Wang B, Liu DL, Li DJ (2011) Pantograph arcing's impact on locomotive equipments. In: 2011 IEEE 57th Holm conference on electrical contacts

14. Ding T, Chen GX, Bu J, Zhang WH (2011) Effect of temperature and arc discharge on friction and wear behaviours of carbon strip/copper contact wire in pantograph-catenary systems. Wear 271(9-10):1629-1636 